\title{
The Investigation of Cortical Auditory Evoked Potentials Responses in Young Adults Having Musical Education
}

\author{
Hanna Garnier ${ }^{1}$, Jakub Wisniewski ${ }^{1}$, Przemyslaw Waszak ${ }^{2}$ \\ ${ }^{1}$ Department of Surgery and Urology for Children and Adolescents, Medical University of Gdansk, Gdansk, Poland \\ ${ }^{2}$ Department of Neurosurgery, Medical University of Gdansk, Gdansk, Poland
}

To the Editor,

We congratulate Zahra Polat and Ahmet Ataş for their work entitled "The Investigation of Cortical Auditory Evoked Potentials Responses in Young Adults Having Musical Education", published in the last issue of Balkan Medical Journal (1). We found the article to be interesting, well written and highly relevant. Investigation of cortical auditory evoked potentials has become an important issue for most of the specialists in the medical field. Their experimental study tests the hypothetical perception differences between musically educated and non-educated subjects. The authors suggest that the musical education seems to impact on the nervous system functioning. However, before drawing conclusions on this topic, certain issues need to be addressed.

According to us the group selection seems to be inadequate. Liesbet Ruytjens et al. (2) suggest that there is a significant sex difference in activation of the primary auditory cortex. They conclude that sex has an impact on the brain activity, thus it should be taken into consideration in the auditory brain studies. The male to female ratio in the Polat \& Ataş' study was 1:3.5 in the control group and 6:7 in the experimental group, which can lead to misleading conclusions, according to the study listed above. It is advised in the experimental studies to remain the gender equality, in order to arrive at more precise conclusions for the further investigations.

The age of the chosen subjects could lead to unintentional bias. Pekkonen et al. (3) discuss the importance of the age-related differences, describing the changes in the auditory cortex (3). Therefore, we would like to emphasize, that the eligible group in Polat \& Ataş' study should be less diverse in age. In their paper subjects' age range between 15.6 and 23.6 years $(n=13)$ and thus should be regarded as a potential confounding factor.

Norton et al. (4) describe congenital implications on the music perception. Students in order to enter the majority of the music schools and academies must undergo special recruitments, based on the tests requiring adequate musical abilities. Therefore to pass these exams children need to show special predispositions right in the beginning of their musical career. It may further explain why people after musical education have significantly different auditory evoked potentials responses. This may be an interesting aspect for the further research. Apart inherited musical aptitudes, the impact of socioeconomic environmental factors on subject's ability to auditory perception seems to be meaningful. We should take into consideration the financial status, education and habitation (urbanized or rural regions) of the subject from each group (experimental and control). It should be evaluated whether the subject comes from the family with musical background or not. These easily estimated factors may have a crucial effect on the study results.

In conclusion, regardless of our concerns, the study by Polat \& Ataş contributed a great deal to the investigation of the cortical auditory evoked potentials responses in young adults having musical education. We believe that this paper will definitely be among the important reports on this subject.

\section{Ethics Committee Approval: N/A.}

\section{Informed Consent: N/A.}

Peer-review: Externally peer-reviewed.

Author contributions: Concept - H.G., J.W., P.W.; Design - H.G., J.W., P.W.; Supervision - H.G. Resource - H.G., J.W., P.W.; Materials - H.G., J.W., P.W.; Data Collection \&/or Processing -.; Analysis \&/or Interpretation - .; Literature Search - H.G., J.W.; Writing - H.G., J.W., P.W.; Critical Reviews - J.W.

Conflict of Interest: No conflict of interest was declared by the authors. 
Financial Disclosure: The authors declared that this study has received no financial support.

\section{REFERENCES}

1. Polat Z, Atas A. The Investigation of Cortical Auditory Evoked Potentials Responses in Young Adults Having Musical Education. Balkan Med J 2015;31:328-34.

2. Ruytjens L, Georgiadis JR, Holstege G, Wit HP, Albers FWJ, Willemsen ATM. Functional sex differences in human primary auditory cortex. Eur J Nucl Med Mol Imaging 2007;34:2073-81.

3. Pekkonen E, Huotilainen M, Virtanen J, Sinkkonen J, Rinne $\mathrm{T}$, Ilmoniemi RJ, et al. Age-related functional differences between auditory cortices: a whole-head MEG study. Neuroreport 1995;6:1803-6.

4. Norton A, Winner E, Cronin K, Overy K, Lee DJ, Schlaug G. Are there pre-existing neural, cognitive, or motoric markers for musical ability? Brain Cogn 2005;59:124-34.

\section{AUTHORS' REPLY}

$$
\text { Zahra Polat }{ }^{1} \text {, Ahmet Ataş² }
$$

${ }^{1}$ Department of Audiology, İstanbul University Faculty of Health Sciences, İstanbul, Turkey

${ }^{2}$ Department of Otorhinolaryngology, Cerrahpaşa Medical Faculty Hospital, İstanbul, Turkey

To the Editor,

We want to thank the authors of the letter for their constructive criticism. Their ideas have helped us and this research area to develop.

The studies in the literature show that although there is a gradual maturation in cortical responses, this maturation is slow and does not make much difference until the age of 12 (1). The age of experiment group in our study was between 15.6 years and 23.6 years. Therefore it can be stated that the age range may not influence the results (2).

There are many studies in the literature stating sex differences in ABR waveforms. But one can find fewer studies about sex difference in CAEP responses. In these studies (3) it is stated that CAEP early components show small sex-related differences mainly in latency but not in amplitude. We also found a small latency difference between the control and experimental group, but this difference was not statistically significant.

Some cortical studies based on PET analysis show some sex differences indicating different cortical functioning between males and females. They found different results for different stimuli. For example, the reference given by the authors of letter states that there was a difference between sex groups when the noise stimuli was used. They also did not find any difference between males and females when a music stimulus was used (4). As a result of this discussion, sex was not accepted as a parameter in our study and the male and female differences were not studied.
However, fMRI studies have identified stronger activation of cortical language processing areas in females, as compared to males, throughout development, which may account for advantages in verbal and written language development seen in females (5). Therefore, in our study, all of the volunteers were examined for delays in physical development and language development and the cases that had normal development participated in the study.

The aim of our study was to investigate the auditory cortical responses in a young musician group when speech signals were used. Therefore, speech sounds extracted from running speech were used as sound stimuli in the study. It was found that there were significant differences between cortical responses of the control and experiment group. There are many studies in the literature indicating the similar results but used a different stimulus (6-8). Moreover, in the literature, training effects of music were also examined and found that both in children and in adults, musical training improves cortical responses (9). Therefore; it is concluded that musical training may improve cortical processing.

However, we share the same ideas and think that the children attending to musical schools have to pass some more complicated exams and need to have other musical abilities, such as: perception and production of pitch; loudness; rhythm; duration of a tone; timbre and tonal memory. Therefore, not every child with an improved CAEP can pursue a successful musical career.

Address for Correspondence: Zahra Polat, Department of Audiology, İstanbul University Faculty of Health Sciences, İstanbul, Turkey

Phone: +902124143000ｅ-mail: zahra_polat@yahoo.com

\section{REFERENCES}

1. Ventura LMP, Costa Filho OA, Alvarenga KF. Central hearing system maturation in normally hearing children. Pro Fono 2009;21:101-7. [CrossRef]

2. Polat Z, Atas A. The investigation of cortical auditory evoked potentials responses in young adults having musical education. Balkan Med J 2015;31:328-34. [CrossRef]

3. Solanki JD, Mehta HB. Sex as a source of variance affecting auditory evoked potential. Egypt J Otolaryngol 2015;31:111-4. [CrossRef]

4. Ruytjens L, Georgiadis JR, Holstege G, Wit HP, Albers FWJ, Willemsen ATM. Functional sex differences in human primary auditory cortex. Eur J Nucl Med Mol Imaging 2007;34:2073-81. [CrossRef]

5. Krizman J, Skoe E, Kraus N. Sex differences in auditory subcortical function. Clin Neurophysiol 2012;123:590-7. [CrossRef]

6. Trainor LJ, Shahin A, Roberts LE. Effects of musical training on the audiotory cortex in children. Ann N Y Acad Sci 2003;999:506-13. [CrossRef]

7. Musacchia G, Strait D, Kraus N. Relationships between behavior, brainstem and cortical encoding of seen and heard speech in musicians and non-musicians. Hear Res 2008;241:34-42. [CrossRef]

8. Bosnyak DJ, Eaton RA, Roberts LE. Distributed auditory cortical representations are modified when non-musicians are trained at pitch discrimination with $40 \mathrm{~Hz}$ amplitude modulated tones. Cereb Cortex 2004;14:1088-99. [CrossRef]

9. Tremblay K, Kraus N, McGee T, Ponton C, Otis B. Central auditory plasticity: changes in the N1-P2 complex after speech-sound training. Ear Hear 2001;22:79-90. [CrossRef] 